\title{
Renal Function Test
}

National Cancer Institute

\section{Source}

National Cancer Institute. Renal Function Test. NCI Thesaurus. Code C74972.

A laboratory procedure that evaluates the kidney function. 